\title{
THE DEFINITION OF DEATH IN ISLAM: CAN BRAIN DEATH BE USED AS A CRITERIA OF DEATH IN ISLAM?
}

\author{
Faroque A. Khan, M.B., FACP, FCCP, FRCP (C)
}

THE DEFINITION OF DEATH IN ISLAM: Can Brain Death Be Used As A Criteria of Death in Islam?

\section{Introduction:}

In recent years, the two most natural human experiences of birth and death have become problematic. Not long ago, it was the case that when a severely handicapped infant was born, or when death approached the elderly, nature took its course. Now we can engineer changes in life, we can sustain life that, hitherto, could not be sustained. Even definition of death is in dispute. Merely possessing the ability to do something, be it genetic engineering, or organ transplants, does not, of course require us to do it. But having the ability requires us to choose. One of the ironies of our century is that the hard sciences have developed much more rapidly than our human ability to accelerate the development of new bioethical structures to guide us in making these difficult decisions.

Death is crowning of life and the final destination of its journey. It is a gate of exit from one life and entry into the other everlasting one. Because death signifies completeness of life, no attempt should be made to bring it forward, for this would be an assault on life. But when death has obviously arrived, no at-

From: Queens Hospital Center, SUNY, Stony

Brook, New York

Further correspondence to Faroque A. Khan, M.B., Chief, Pulmonary Medicine, Queens Hospital Center, 82-68 164th Street, Jamaica, NY 11432

Part of this paper was presented at the syposium on Brain Death, at the 17th annual convention of the Islamic Medical Association in Niagara, Buffalo, NY on Friday, July 4, 1985. tempt should be made to stretch the process of dying for this will only be futile, wasteful and painful. Death is as old as history, but scientific definition of the exact moment of death is of course subject to the precision and accuracy of our scientific tools and accumulation of our knowledge.

Pushing back the beginning and end times of life, have often left the scientific community, confused, religious community grappling for the words and structures in which to deal with these new boundaries or lack thereof, and leave the lay people kind of caught in the middle. This article will attempt to focus on some of the contemporary issues particularly regarding those dealing with life and death according to Islamic principles.

\section{Historical:}

The definition of death has been debated in scientific literature. While the old classic definition of cessation of cardiac and respiratory function is still valid in instances where death occurs in an environment where life support systems are not available (home), it is quite a different story if death occurs in an institution. Most often Americans can expect to go through the tortures of the damned before they are allowed to die of cancer, heart or lung failure, or pure senile decay. Several authors have suggested that brain death can be defined as occurring in an individual who has sustained: a.) irreversible cessation of circulatory and respiratory functions, $b$.) irreversible cessation of all functions of the entire brain, including brain stem. The determination of death must be made in accordance with accepted medical standards. This definition has now been legally accepted in 37 out the total 50 states of the United States of America. There are those who disagree with the concept of brain death on moral, and scientific grounds. Thus, there is no uniformity for defining death from a scientific viewpoint. 


\section{Religious Definition of Death:}

The sanctity of life and the inevitable occurrence of death for all mankind has been stressed in Islam.

- Quran 3:185 - Every soul shall have a taste of death.

- Quran 39:30 - Truly thou wilt die (one day), and truly they (too) will die (one day)

- Quran 3:145 - Nor can a soul die except by God's leave, the term being fixed as by writing.

- Quran 39:42 - Allah takes away the souls upon their death; and of those who do not die during their sleep, those on whom He has passed the decree of death He keeps with Him and the rest $\mathrm{He}$ restores for a term ordained. Verily in this are signs for those who reflect.

While the inevitability of death is made fairly clear in the above verses, the exact definition of death remains vague. Just as the inevitable occurrence of death is well defined, the sanctity of human life has also been abundantly stressed in Islam.

- Quran 2:195 - And do not with your own hands cast yourselves into destruction.

— Quran 4:29 - Nor kill (or destroy) yourselves: For verily God hath been to you most merciful.

- Quran 17:31 - And slay not your children for fear of want. We shall provide for them and for you. Lo! Their slaying is a great sin.

- Quran 5:35 - Whosoever killeth a human being for other than manslaughter or corruption in the earth, it shall be as if he had killed all mankind, and whosoever saveth the life of one, it shall be as if he had saved the life of all mankind.

Thus, Islam advocates that every effort should be made to preserve life, take good care of the body and at a predetermined time death will occur and spare no one.

While the issues of life and death have been discussed, in the Islamic teachings, the exact definition of death has not been clearly identified. In the Quranic Sura 23 verse 100 the stages of life are described as: a. the life in this world; b. the moment of death when the body and the soul are separated. The body is returned to the earth and the soul is in a state of Barzakh, partition, a quiescent state until the judgement comes; $c$. the day of resurrection and the final stage of life.

Thus it appears that Islam does not clearly identify and define the moment when death occurs.

How valid are the usually applied criteria of cessa- tion of Cardiac and Respiratory Functions as indicators of death?:

\section{A. Cessation of Breathing:}

There are numerous instances when adults and children have difficulty in maintaining spontaneous breathing, in the presence of preserved other body functions. Such patients can be sustained with various life support systems and can lead a productive life for long periods of time. A few examples include paralysis of the respiratory center caused by infectious agents such as - poliomyelitis. Large numbers of such patients were seen, in the western world, prior to the introduction of polio vaccination, and such patients were maintained on artificial breathing devices till the time the infection cleared up. This problem is still quite common in countries where poliomyelitis exists. Obviously, if one were to define death as the absence of spontaneous breathing, these patients would be classified as dead, even though all other bodily functions are quite intact in such patients. Several other diseases have been associated with an absent or impaired breathing in the presence of preserved body function, such as - bilateral diaphragmatic paralysis, traumatic cervical spinal cord transection, bilateral cervical cordotomy. These conditions are characterized by the lack of, or the impairment of, a spontaneous respiratory drive and with artificial breathing devices or phrenic nerve pacers, such patients can be sustained for prolonged periods of time. Thus, in modern day medicine, there are instances where the breathing may be absent or impaired while the rest of the body function are intact and the patient can lead a reasonable life. Thus, one can not use the sole absence of breathing as an indicator of death.

\section{B. Does the Absence of Natural Heart Beat Define Death?:}

Major cardiac surgical procedures often require cardiopulmonary bypass. During the cardiopulmonary bypass, the heart beat is stopped for periods which can extend for several hours, and during this period, the patient's life is sustained by the artificial bypass machine. It was estimated that in 1984, approximately 300,000 , such procedures were performed in the US. Thus the absence of natural heart beat under these circumstances, would not be defined as death, since the large majority of such individuals undergo the operation successfully and are returned back to useful life. During 1984 and 1985, numerous examples of removal of the heart and its replacement, 
either with a human heart, mechanical heart or a Baboon's heart, have been broadly publicized and some of these patients continue to live for prolonged periods of time. Similarly, other instances could be sited, such as complete heart blocks, where the placement of a pacemaker allows these patients to continue leading useful life for long periods of time. Therefore, similar to the discussion on the lack of spontaneous breathing, I believe that lack or the impairment of natural heart beat can not be used as a sole criteria of death.

\section{What Alternatives are There?:}

The two examples cited above, should make it abundantly clear that the cessation of the heart beat and the breathing can not be used as a sole critieria of death. This traditional definition of death would suffice when death occurs at home and the means of artificial life support systems are not available but the large majority of deaths, in the western world, occur in institutions. Therefore, in an institutionalized patient, one has to be clear regarding the approach to the use of artificial support systems. Increasing number of medical centers and the majority of the states in the US are now accepting brain death as being equivalent to death. Large numbers of studies have shown that patients who fulfill all the scientific criteria of brain death, when followed for periods of time do not survive. Therefore, while one can maintain the breathing and heart beat with artificial means, if the person exhibits signs of brain death, it can be equated with death. New York State, in 1985, joined the remaining 37 states in accepting, legally, brain death as being equivalent to death.

\section{Does the Acceptance of Brain Death as a Criteria for Death Violate Any Islamic Principles?:}

In my review of the Islamic jurisprudence, I was unable to find any statement which specified the time for death. However the Islamic view of the components of a person are amply defined and these include, i.e. NAFS (self), ROOH (spirit), and QALB (spiritual heart or mind); and the features and functions of these components have been well described. All the above mentioned components of the person coincide with the functions of the brain alone - other scholars also agree that the physical manifestation of death, as detailed in Islamic jurisprudence, are present only with brain death and with the death of no other organ. I believe this was done with a purpose in mind, in that, with the changing time and technology, the criteria and definitions of death would change and therefore, we as Muslims are left with very broad based outline whereby the standards and definition can be adapted depending on the state of science and the technical skills available. Therefore, I believe that accepting brain death as a criteria of death, does not violate any Islamic principle. This should come as comfort to those of us who deal with critically ill patients and have to grapple with the issues of life and death on an ongoing basis. Whereas the sanctity of life and the inevitablity of death has been made abundantly clear in our religion, the exact definition of death has been kept vague in order for us to allow to grapple with these issues from time to time. The following Hadith best exemplifies the use of Qiyas and IJMA in grappling with difficult problems which are not clearly addressed to in either the QURAN or HADITH -

Maadh - ibn-i-Jabal (r.a), The Governor designate for YEMEN paid a visit to Prophet to take his leave before departure. The following conversation took place:

Prophet - On what basis shalt thou decide and judge cases?

Maadh - According to the Book of God (Quran).

Prophet - And if thou dost not find any provision therein?

Maadh - Then according to the conduct of the Messenger of God (Prophet Muhammad Pbuh).

Prophet - And if thou dost not find provision therein?

Maadh - Well, then, I shall make every effort with my own opinion. The prophet was so delighted at this reply that he exclaimed "Praise be to God who hath guided the envoy of His envoy to what pleaseth the envoy of God."'

\section{Conclusion:}

In this article I have attempted to focus on some of the contemporary ethical issues which face physicians and patients alike, particularly in the Western world. These issues have assumed great relevance due to the rapidly enlarging field of technology which permits the continuation of vital body functions, sometimes for indefinite periods of time. Islam stresses the value and sanctity of life, while the inevitability of death and respect for the dead is also emphasized. We, as physicians, are urged to make every effort to relieve suffering, however, due respect for the dead is urged and violation of the dead is unacceptable in Islam. There are occasions when distinction between the dead and the living are not clear, under such circumstances equating the presence of brain death with real death, is permissible under the Islamic guidelines. We, as Muslims, have also been instructed, that when doubt persists and confusion prevails, the use of IJMA and Qiyas, allow us as Muslims physicians, to make intelligent choices and recommendations such as in dealing with critically ill patients, and advocating the use of brain death as a criteria of death. 


\section{References:}

1. Lynn J: The determination of death. Ann Int Med 99:264, August 1983 (editorial).

2. Jonsen AR: A concord in medical ethics. Ann Int Med 99:261, August 1983 (edit.).

3. Friel PB: Death and dying. Ann Int Med 97:767-771, November 1982.

4. Appel JZ: Ethical and legal questions posed by recent advances in medicine. J.A.M.A. 205:513-16, 1968.

5. A definition of irreversible coma. Report of the Ad Hoc Committee of the Harvard Medical School to examine the definition of Brain Death. J.A.M.A. 205:337-340, 1968.

6. Bernat, JL, Culver CM, and Gert B: On the definition and criterion of death. Ann Int Med 94:389-394, 1981.

7. Black P: Brain death. New Eng J Med 299:338-344 and 393-401, 1978.
8. Veith FJ, Fein JM, Tendler MD, Veatch RM, Kleiman MA, and Kalkines G: Brain Death I. A status report of medical and ethical considerations. J.A.M.A. 238:1651-55 and 1744-48, 1977.

9. Byrne PA, O'Reilly S and Quay PM: Brain death: An opposing viewpoint. J.A.M.A. 242:1985-1990, 1979.

10. Youngner SJ, Bartlett ET: Human death and high technology: The failure of the whole brain formulations. Ann Int Med 99:252-58, August 1983.

11. Khan F: Ethics of critically ill patients. An Islamic viewpoint. J Islamic Med Assoc 15:105-09, 1983.

12. Elkadi A: Brain Death. Religious aspects. J Islamic Med Assoc 17:107, 1985 (abst).

13. Lo B: Death of Clarence Herbert. Withdrawing care is not murder. Ann Int Med 101:248-251, 1984.

14. Felderman DM: Rabbinic Comment. Definition of death and dying. The Mt. Sinai J of Med 5(1): 73-76, Jan-Feb 1984.

15. Kabakow B: The definition of death and dying. The Mt. Sinai J of Med 51(1):69-72, Jan-Feb 1984. 